\title{
Repositioning chlorpromazine for treating chemoresistant glioma through the inhibition of cytochrome c oxidase bearing the COX4-1 regulatory subunit
}

\author{
Claudia R. Oliva ${ }^{1}$, Wei Zhang ${ }^{2}$, Cathy Langford ${ }^{1}$, Mark J. Suto ${ }^{2}$, Corinne E. Griguer ${ }^{1,3}$ \\ ${ }^{1}$ Department of Neurosurgery, University of Alabama at Birmingham, Birmingham, 35294 Alabama, USA \\ ${ }^{2}$ Southern Research, Birmingham, 35294 Alabama, USA \\ ${ }^{3}$ Center for Free Radical Biology, University of Alabama at Birmingham, Birmingham, 35294 Alabama, USA
}

Correspondence to: Corinne E. Griguer, email: cegriguer@uabmc.edu

Keywords: cytochrome c oxidase, chlorpromazine, glioblastoma, inhibitor, stem cells

Received: December 30, $2016 \quad$ Accepted: April 07, $2017 \quad$ Published: April 19, 2017

Copyright: Oliva et al. This is an open-access article distributed under the terms of the Creative Commons Attribution License (CC-BY), which permits unrestricted use, distribution, and reproduction in any medium, provided the original author and source are credited.

\section{ABSTRACT}

Patients with glioblastoma have one of the lowest overall survival rates among patients with cancer. Standard of care for patients with glioblastoma includes temozolomide and radiation therapy, yet $30 \%$ of patients do not respond to these treatments and nearly all glioblastoma tumors become resistant. Chlorpromazine is a United States Food and Drug Administration-approved phenothiazine widely used as a psychotropic in clinical practice. Recently, experimental evidence revealed the anti-proliferative activity of chlorpromazine against colon and brain tumors. Here, we used chemoresistant patient-derived glioma stem cells and chemoresistant human glioma cell lines to investigate the effects of chlorpromazine against chemoresistant glioma. Chlorpromazine selectively and significantly inhibited proliferation in chemoresistant glioma cells and glioma stem cells. Mechanistically, chlorpromazine inhibited cytochrome c oxidase ( $\mathrm{CcO}$, complex IV) activity from chemoresistant but not chemosensitive cells, without affecting other mitochondrial complexes. Notably, our previous studies revealed that the switch to chemoresistance in glioma cells is accompanied by a switch from the expression of $\mathrm{CcO}$ subunit 4 isoform 2 (COX4-2) to coX4-1. In this study, chlorpromazine induced cell cycle arrest selectively in glioma cells expressing COX4-1, and computer-simulated docking studies indicated that chlorpromazine binds more tightly to $\mathrm{CcO}$ expressing $\mathrm{COX4-1}$ than to $\mathrm{CcO}$ expressing coX4-2. In orthotopic mouse brain tumor models, chlorpromazine treatment significantly increased the median overall survival of mice harboring chemoresistant tumors. These data indicate that chlorpromazine selectively inhibits the growth and proliferation of chemoresistant glioma cells expressing cox4-1. The feasibility of repositioning chlorpromazine for selectively treating chemoresistant glioma tumors should be further explored.

\section{INTRODUCTION}

Temozolomide (TMZ), an alkylating agent that has shown significant initial benefit in the treatment of high-grade gliomas, especially when combined with radiotherapy, is commonly used in the adjunctive treatment of gliomas. However, TMZ chemotherapy eventually becomes impaired by the development of chemoresistance. Indeed, this phenomenon presents the most challenging barrier in the successful treatment of cancer and is the principal reason for chemotherapy failure and one of the main reasons underlying the failure to demonstrate a sustainable beneficial clinical outcome for patients with glioblastoma (GBM) $[1,2]$.

Differentiated bulk tumor cells commonly use less efficient glycolysis for the production of ATP (Warburg effect) [3]. However, tumors also contain cancer stem cells (CSCs), a subset of cancer cells that have the ability to 
repopulate the entire tumor and thus lead to recurrence. Distinct metabolic phenotypes have been described for CSCs, depending on the cancer type [4]. The concept of glycolysis-driven CSCs has been demonstrated in breast cancer [5], nasopharyngeal carcinoma [6], and hepatocellular carcinoma [7]. Conversely, CSCs driven by mitochondrial oxidative phosphorylation (OxPhos) have been identified in lung cancer [8,9], glioma [10-12], pancreatic cancer [13], and leukemia stem cells [14]. Regardless of the primary metabolic phenotype, however, mitochondrial function appears to be critical for CSC functionality, and elimination of highly chemoresistant CSCs via inhibition of mitochondrial function may prevent relapse from disease and thus improve patients' long-term outcome [4].

Cytochrome c oxidase $(\mathrm{CcO})$ is the terminal enzyme of the mitochondrial respiratory chain (electron transport chain, ETC) that catalyzes the transfer of electrons from cytochrome c (cyt c) to oxygen $\left(\mathrm{O}_{2}\right)$. Mammalian $\mathrm{CcO}$ is a complex enzyme that comprises three mitochondrial DNA-encoded subunits that perform the catalytic function and 10 nuclear-encoded subunits that regulate the catalytic activity $[15,16]$. CcO activity governs the electron flux capacity of the ETC, thus controlling the efficiency of mitochondrial coupling and thereby the production of reactive oxygen species (ROS) [12, 17-19].

Several studies have focused on the biological functions of $\mathrm{CcO}$ subunits in the development of tumors. Chen et al. reported that knockdown of $\mathrm{CcO}$ subunit 5a (COX5a) expression substantially suppresses the migration and invasion of non-small cell lung cancer cells through inhibition of metalloproteinases MMP-2 and MMP-9 [20]. Moreover, elevated COX5a expression is associated with higher $\mathrm{N}$ stage (a parameter that indicates cancer spread to the nearby lymph nodes) and poorer prognosis of patients with lung adenocarcinoma. Additionally, COX5b is involved in the metastatic potential of colorectal carcinoma cells [21]. Notably, $\mathrm{CcO}$ subunit isoform expression can vary by tissue and developmental stage [22] and may also regulate $\mathrm{CcO}$ activity. In $\mathrm{GBM}$, increased $\mathrm{CcO}$ activity and increased expression of $\mathrm{CcO}$ subunit 4 isoform 1 (COX4-1) have been associated with acquisition of TMZ chemoresistance [12] as well as shorter progression-free and overall survival of patients [23].

$\mathrm{COX} 4$ performs an essential regulatory role in $\mathrm{CcO}$ by binding ATP (allosteric inhibitor) and ADP (allosteric activator), thereby adjusting energy production to energy demand [24-27]. These alterations are likely to facilitate adaptive chemoresistance through the suppression of apoptotic signaling [28]. Indeed, inhibition of $\mathrm{CcO}$ activity or decreased expression of COX4-1 reverses chemoresistance to $\mathrm{TMZ}[12,17]$, supporting a close correlation between acquired chemoresistance and changes in cellular metabolic machinery at the level of the mitochondrion. Thus, a mechanism to therapeutically target $\mathrm{CcO}$ activity may provide substantial benefit to patients with GBM.
Chlorpromazine (CPZ) is one of the oldest drugs developed as an antipsychotic agent [29-31], but interest in this drug has been revived as the anti-cancer activity of CPZ has been demonstrated experimentally in many cancers, including glioma [32-38]. However, the specificity of CPZ as an agent against chemoresistant glioma has never been tested. Remarkably, it was reported $>50$ years ago that $\mathrm{CPZ}$ affects mitochondrial function by blocking $\mathrm{CcO}$ activity [39, 40], but the therapeutic relevance of mitochondrial activity, and thus of this finding, was not apparent at the time. Therefore, the mechanisms by which $\mathrm{CPZ}$ blocks $\mathrm{CcO}$ activity as well as the therapeutic potential of this effect remain unknown. To obtain insight into the action of CPZ in the regulation of $\mathrm{CcO}$ and the anti-glioma properties of $\mathrm{CPZ}$ against TMZresistant cells, we analyzed $\mathrm{CcO}$ activity, cell cycle control, and long-term clonogenic survival in glioma cells after CPZ treatment. We found that CPZ specifically inhibits $\mathrm{CcO}$ activity in chemoresistant glioma cells, including glioma stem cells (GSCs) derived from patient xenolines.

\section{RESULTS}

\section{CPZ inhibits proliferation in chemoresistant glioma and GSCs}

Because we hypothesized that CPZ has an antiproliferative effect on chemoresistant glioma, the effect of CPZ on cell survival and growth was examined. We first used the TMZ-sensitive human glioma cell line U251 and a U251-derived TMZ-resistant cell line (UTMZ) previously described [11]. Treatment with CPZ induced inhibition of cell proliferation in UTMZ cells with an $\mathrm{IC}_{50}$ of $13.12 \pm 2.8 \mu \mathrm{M}$. In contrast, $\mathrm{CPZ}$ did not affect cell proliferation of TMZ-sensitive U251 cells at concentrations up to $30 \mu \mathrm{M}$ and with treatment times up to $96 \mathrm{~h}$ (Figure 1A). CPZ also significantly inhibited anchorage-independent growth of UTMZ cells $(p<0.001)$ in soft agar growth assays (Figure 1B). Because CPZ blocked cell proliferation specifically in chemoresistant glioma cells, we investigated whether CPZ blocks cell proliferation in the proportion of TMZ-resistant cells that have GSC properties. As illustrated in Figure 1C, when cultured in serum-free culture medium supplemented with epidermal growth factor (EGF) and basic fibroblast growth factor (bFGF), TMZ-resistant UTMZ cells formed neurospheres ranging from 0.1 to $1 \mathrm{~mm}$ in diameter. However, when UTMZ cells were cultured in the presence of CPZ, smaller and fewer neurospheres developed, ranging from 2.5 to $10 \mu \mathrm{m}$ in diameter. When cells were plated in an in vitro limiting dilution assay, CPZ also inhibited the formation of tumor neurospheres in a dosedependent manner (Figure 1D).

\section{CPZ inhibits CcO activity}

CPZ has been reported to target mitochondrial function $[39,40]$, thus we tested whether CPZ targets 
the mitochondrial ETC complexes. The activities of complexes I, II-III, IV (CcO) and V (ATP synthase) were measured in mitochondrial extracts from TMZsensitive U251 and TMZ-resistant UTMZ cells in the presence of differing CPZ concentrations (Figure 2). Although CPZ did not affect complexes I, II-III, or $\mathrm{V}$ (Figure 2A, 2B and 2D), it significantly decreased $\mathrm{CcO}$ activity in a dose-dependent manner (Figure 2C) specifically in UTMZ cells. We next investigated the kinetic mechanism of $\mathrm{CPZ}$ inhibition of $\mathrm{CcO}$. $\mathrm{CPZ}$ lowered the Vmax $(870 \pm 57$ to $375 \pm 24 \mathrm{pmol} / \mathrm{sec} / \mathrm{mg})$ but not the $\mathrm{Km}$ for cyt c. Figure 2E shows the representative Michaelis-Menten graph, and Figure 2F shows the representative Lineweaver-Burk double-reciprocal plots indicating a non-competitive inhibition of cyt c, with a $50 \%$ decrease in Vmax at $2 \mu \mathrm{M} \mathrm{CPZ}$.
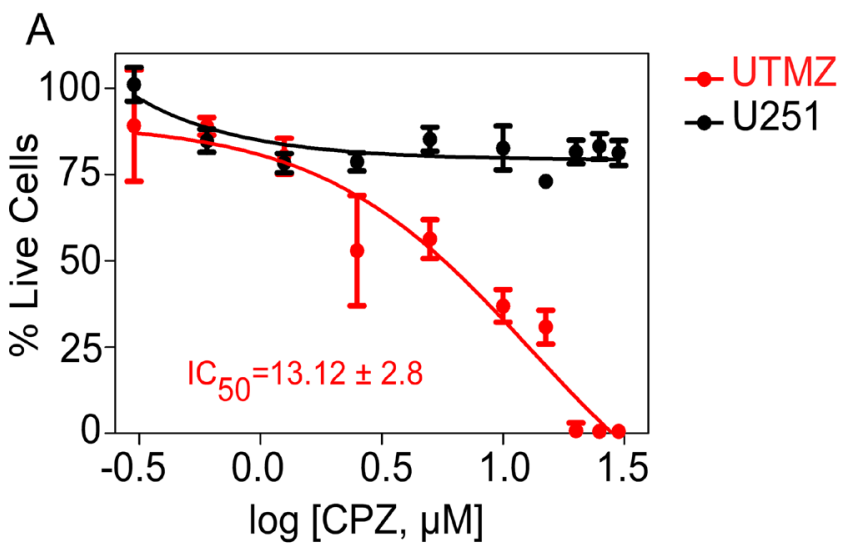

B

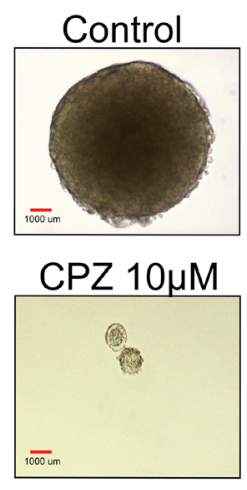

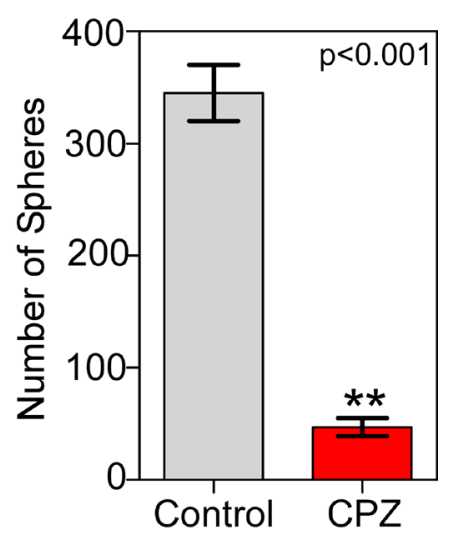

C

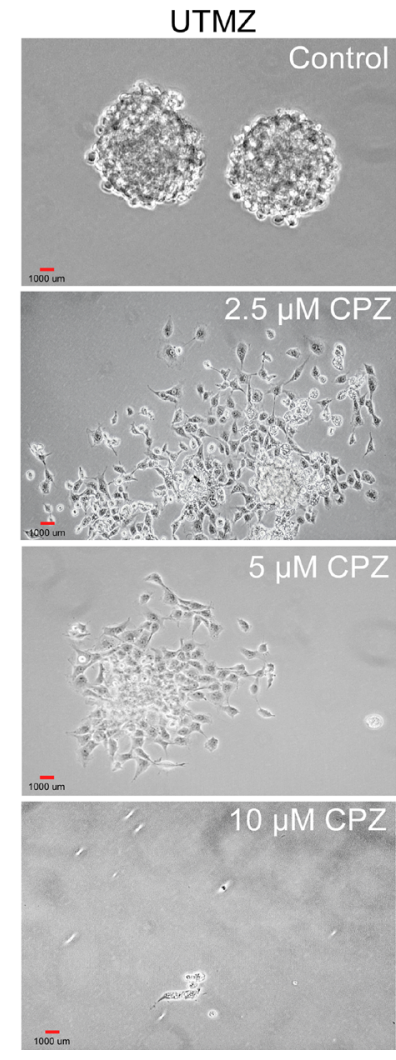

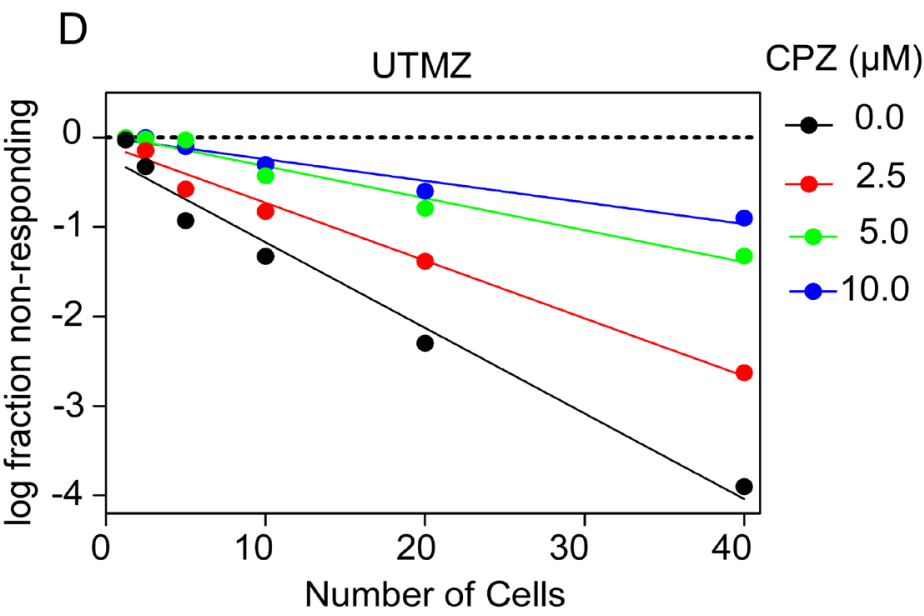

\begin{tabular}{|c|c|}
\hline Condition & $\begin{array}{c}\mathbf{1 / ( S t e m ~ C e l l ~ F r e q u e n c y ) ~} \\
{[\mathbf{9 5 \%} \mathrm{Cl}]}\end{array}$ \\
\hline Control & $8.56[6.8-11.3]$ \\
\hline $2.5 \mu \mathrm{M} \mathrm{CPZ}$ & $35.68[28.5-43.7]$ \\
\hline $5 \mu \mathrm{M} \mathrm{CPZ}$ & $62.8[52.4-71.5]$ \\
\hline $10 \mu \mathrm{M} \mathrm{CPZ}$ & $82.5[76.2-88.8]$ \\
\hline
\end{tabular}

Figure 1: Effect of CPZ on proliferation of TMZ-resistant cells. (A) Effect of CPZ on TMZ-sensitive U251 and TMZ-resistant UTMZ glioma cell proliferation. Cells were treated with CPZ at the indicated concentrations. (B) Anchorage-independent growth, assessed by colony formation of UTMZ cells in semisolid medium. Cells were grown on soft agar plates for 3 weeks before colonies were visualized microscopically. Left panel: Representative micrographs of vehicle-treated (top) and CPZ-treated cells (bottom). Right panel: Quantification of colony formation. Colonies were counted in a blinded fashion. (C) Representative micrographs from in vitro limiting dilution assays with GSCs treated with PBS or CPZ at the indicated concentrations. (D) Quantification of GSCs in the respective assays in (C). Results represent the average from two independent experiments. 
Because we previously demonstrated that the expression of COX4-1, rather than COX4-2, is in part responsible for the expansion of GSCs [11], the cells implicated in tumor recurrence and resistance to therapy in patients with glioblastoma, we tested the effect of CPZ in U251 glioma cells transfected with FLAG-epitope-tagged COX4-1 (U251-TgCOX4-1) or FLAG-epitope-tagged COX4-2 (U251-TgCOX4-2). U251 cells express the COX4-2 isoform, thus the vectors were transfected into U251 cells stably depleted of endogenous COX4-2 [11]. As illustrated in Figure 3, CPZ inhibited $\mathrm{CcO}$ activity and decreased the proliferation of cells that expressed the COX4-1 isoform, with an $\mathrm{IC}_{50}$ of $1.04 \mu \mathrm{M}$ (Figure 3B).

To provide evidence that cell treatment with $\mathrm{CPZ}$ inhibits $\mathrm{O}_{2}$ consumption, we investigated the cellular bioenergetic response to $\mathrm{CPZ}$ by high-resolution respirometry. A comparison of different parameters in COX4-1- and COX4-2-expressing glioma cells is provided in Figure 3. Under basal conditions, CPZ-
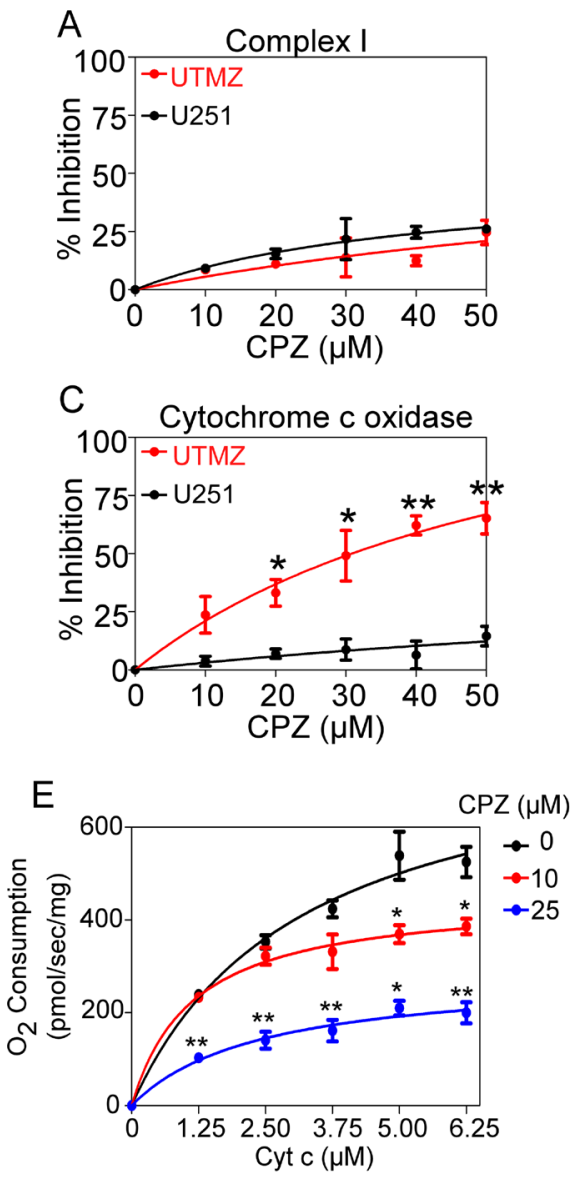

treated COX4-1 glioma cells had markedly lower basal mitochondrial respiration than untreated COX4-1expressing cells had (Figure 3C, 3D). This mitochondrial respiration is composed of two components: the $\mathrm{O}_{2}$ consumption related to ATP synthesis and the $\mathrm{O}_{2}$ consumption due to the proton leak across the inner mitochondrial membrane. The addition of oligomycin, an ATP synthase inhibitor, allowed the differentiation of these two parameters. While there was no significant difference in proton leak, the ATP-linked respiration was significantly reduced in COX4-1 cells pretreated with CPZ (Figure 3C, 3D). The addition of the uncoupler FCCP allowed the determination of the potential maximal respiratory capacity of the cells. COX4-1-expressing cells pretreated with $\mathrm{CPZ}$ had a markedly lower maximum respiratory rate than untreated COX4-1-expressing cells had (Figure 3C, 3D). Compared with COX4-1-expressing glioma cells, COX4-2-expressing glioma cells have a reduced respiratory capacity. Notably, CPZ did not
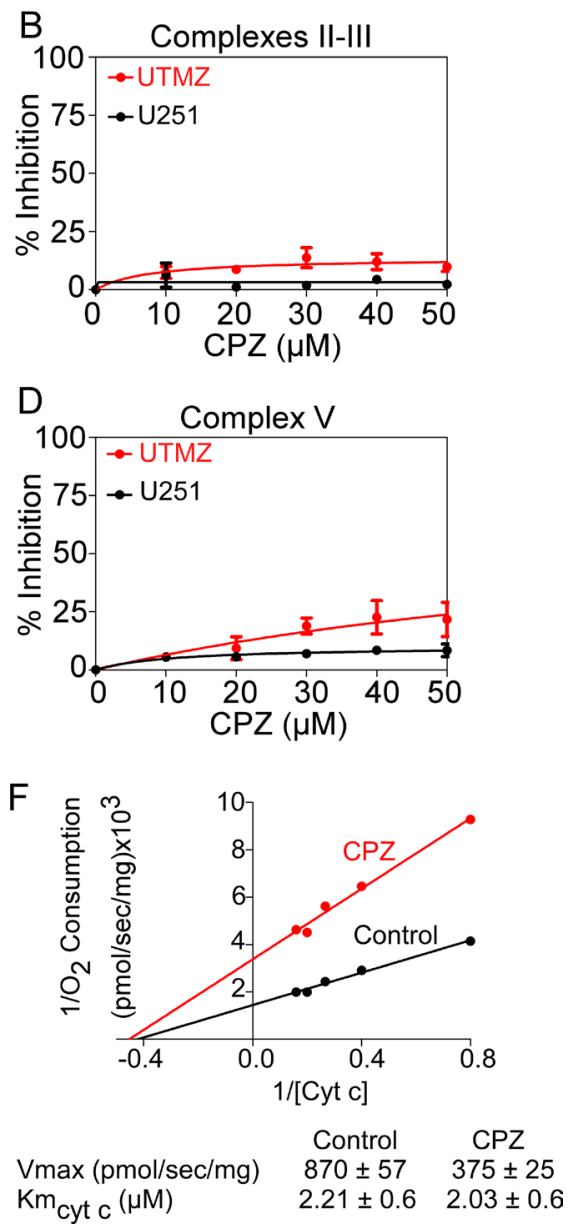

Figure 2: Effects of CPZ on mitochondrial complexes. (A-D) CPZ was tested on mitochondrial extracts from TMZ-sensitive U251 and TMZ-resistant UTMZ glioma cells to determine the effects on the activity of complex I (A), II-III (B), CcO (complex IV) (C), and complex V (D) of the mitochondrial transport chain. Graphs represent the activity level of each complex in the presence of PBS (control) or CPZ (up to $50 \mu \mathrm{M}$ ). The results are averages from triplicate determinations from two independent experiments. (E) Representative Michaelis-Menten graph depicting the inhibition of cyt c activity by CPZ. (F) Representative Lineweaver-Burk double-reciprocal plots indicating a non-competitive inhibition of cyt c, with a $50 \%$ decrease in Vmax at $2 \mu \mathrm{M} \mathrm{CPZ.}{ }^{*} p<0.05$; ${ }^{* *} p<0.01$; and ${ }^{* * *} p<0.001$. 
induce significant differences in basal, ATP-linked, or maximal respiration in glioma cells expressing COX4-2, suggesting that the lack of COX4-1 isoform makes the cells insensitive to CPZ (data not shown).

When cells overexpressing COX4-1 were plated in an in vitro limiting dilution assay, $\mathrm{CPZ}$ inhibited the formation of tumor neurospheres and the frequency of self-renewing cells in a dose-dependent manner (Figure 3E, 3F). The detection of CPZ-mediated inhibition of $\mathrm{CcO}$ activity only when the COX4-1 subunit was expressed suggests that $\mathrm{COX} 4$ isoform-specific differences in $\mathrm{CcO}$ structure may control the effects of $\mathrm{CPZ}$ on $\mathrm{CcO}$.

We next investigated the effect of CPZ on mitochondrial extracts from GSCs derived from $\mathrm{J} \times 12$ and $\mathrm{J} \times 39$ human tissue. Western blot analysis of the COX 4 subunits showed that both human GSC types expressed significantly higher levels of COX4-1 than of COX4-2 (Figure 4A and 4B). CPZ also decreased $\mathrm{CcO}$ activity in GSCs derived from both $\mathrm{J} \times 12$ and $\mathrm{J} \times 39$ xenolines (Figure 4C and 4D). Similarly, CPZ significantly decreased the stem cell frequency and the frequency of self-renewing cells in a dose-dependent manner in both xenolines (Figure 4E and 4F).

\section{CPZ induces cell cycle arrest in TMZ-resistant glioma cells}

To evaluate the inhibitory effect of CPZ on cell proliferation, we measured cell-cycle progression using flow cytometry. TMZ-sensitive U251 and TMZ-resistant UTMZ cells were treated with 10 or $20 \mu \mathrm{M}$ of CPZ, and the percentage of cells in each stage of the cell cycle
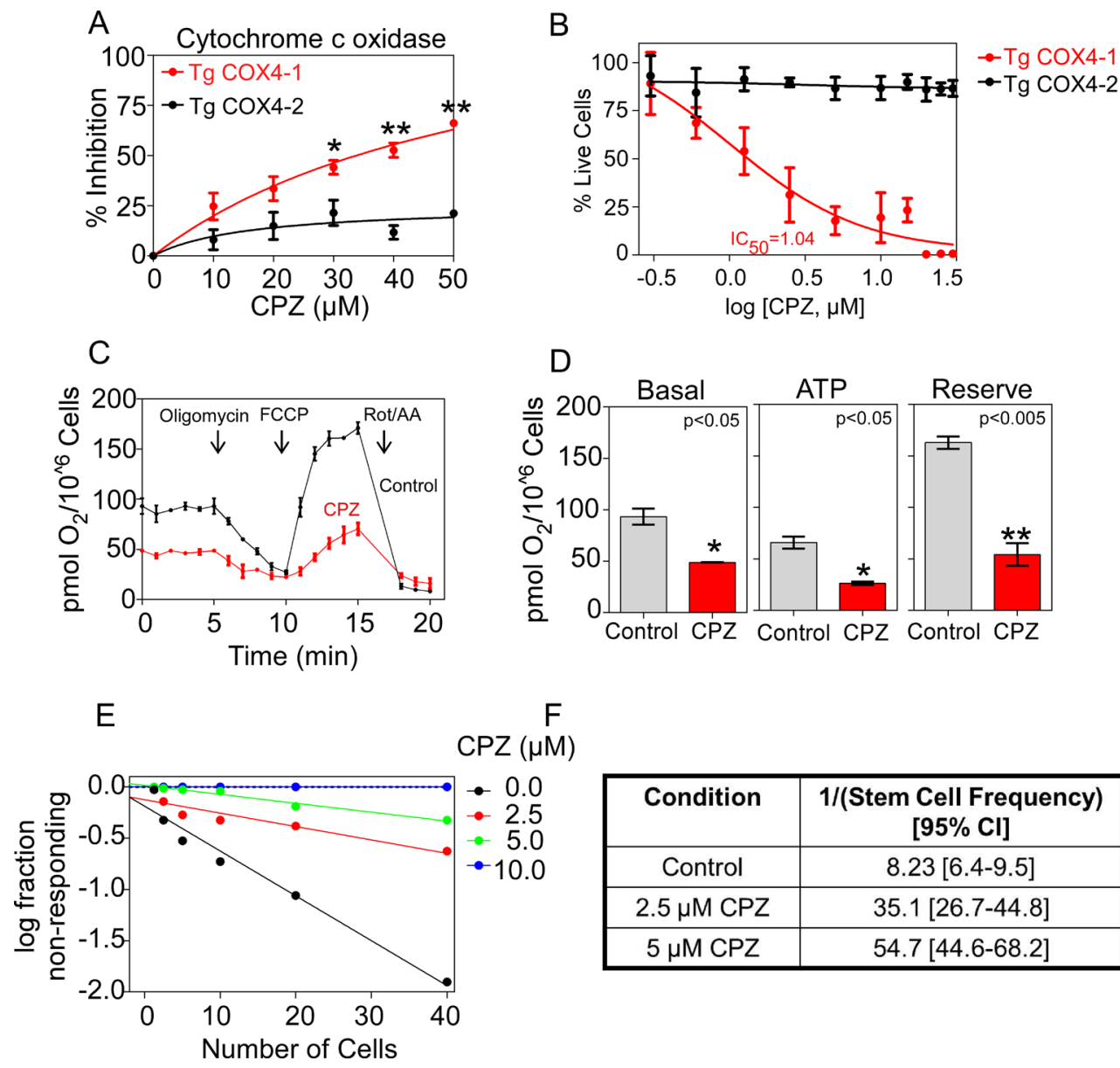

\begin{tabular}{|c|c|}
\hline Condition & $\begin{array}{c}1 / \text { (Stem Cell Frequency) } \\
{[95 \% \text { Cl] }}\end{array}$ \\
\hline Control & $8.23[6.4-9.5]$ \\
\hline $2.5 \mu \mathrm{M} \mathrm{CPZ}$ & $35.1[26.7-44.8]$ \\
\hline $5 \mu \mathrm{M} \mathrm{CPZ}$ & $54.7[44.6-68.2]$ \\
\hline
\end{tabular}

Figure 3: Effects of CPZ on CcO expressing COX4-1 or COX4-2 isoform. (A) The effect of CPZ on CcO activity was tested in mitochondrial extracts from cells with $\mathrm{CcO}$ expressing COX4-1 (TgCOX4-1) or COX4-2 (TgCOX4-2). Graphs represent the level at which $\mathrm{CcO}$ activity is inhibited in the presence of PBS (control) or CPZ (up to $50 \mu \mathrm{M}$ ). The results are averages from triplicate determinations from two independent experiments. (B) Effect of CPZ on the proliferation of cells with CcO expressing COX4-1 or COX4-2. (C) Bioenergetic profile of TgCOX4-1 intact cells in the presence of PBS (control) or CPZ (5 $\mu \mathrm{M})$. Oxygen consumption was measured using sequential injection of oligomycin $(2 \mu \mathrm{g} / \mathrm{ml}), \mathrm{FCCP}(1 \mu \mathrm{M})$, and antimycin A $(2.5 \mu \mathrm{M})$. (D) Basal respiration, ATP-linked respiration and reserve respiratory capacity are shown. Results represent the means \pm SD of 3 independent experiments. (E) and (F) In vitro limiting dilution assays and quantification of GSCs from cells with $\mathrm{CcO}$ expressing COX4-1 and treated with CPZ at the concentrations indicated. Results are the average from two independent experiments. ${ }^{*} p<0.05 ; * *<0.01$; and ${ }^{* * *} p<0.001$. 
was determined $24 \mathrm{~h}$ after treatment, as described in the materials and methods section.

In agreement with the results of the proliferation studies (Figure 1A), CPZ treatment of U251 cells did not affect the percentage of cells in the $\mathrm{G} 1$ phase (Figure 5A). However, CPZ treatment of UTMZ cells led to G1 phase accumulation that reached $70.4 \%(p<0.0001)$ and $73.1 \%$ $(p=0.0028)$ after treatment with 10 and $20 \mu \mathrm{M} \mathrm{CPZ}$, respectively, whereas only $52.6 \%$ of control vehicle-treated UTMZ cells were in G1 (Figure 5B). Concomitantly, $12.1 \%$ of UTMZ cells in the $20 \mu \mathrm{M}$ CPZ group were in the $\mathrm{S}$ phase fraction compared with $22.7 \%$ of the cells in the control group. Similarly, $12.2 \%$ of UTMZ cells in the
$20 \mu \mathrm{M} \mathrm{CPZ}$ group were in the $\mathrm{G} 2 / \mathrm{M}$ fraction compared with $23.6 \%$ of cells in the control group. These results indicate that $\mathrm{CPZ}$ causes inhibition of cell proliferation in TMZ-resistant cells by G1 cell cycle arrest.

Because CPZ blocks $\mathrm{CcO}$ activity and cell proliferation when COX4-1 is expressed, we next compared the effect of $\mathrm{CPZ}$ on cell cycle progression in glioma cells transfected with COX4-1 (U251TgCOX4-1) or with COX4-2 (U251-TgCOX4-2). As shown in Figure 5C and 5D, CPZ triggered cell cycle arrest only when cells expressed COX4-1. Indeed, the percentage of glioma cells transfected with TgCOX4-1 accumulated in the G1 phase increased from $52.8 \%$ in
A

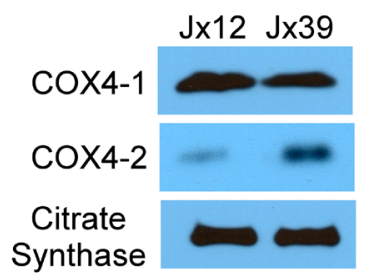

C

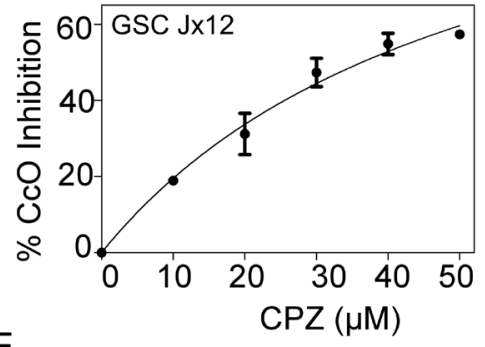

$\mathrm{E}$

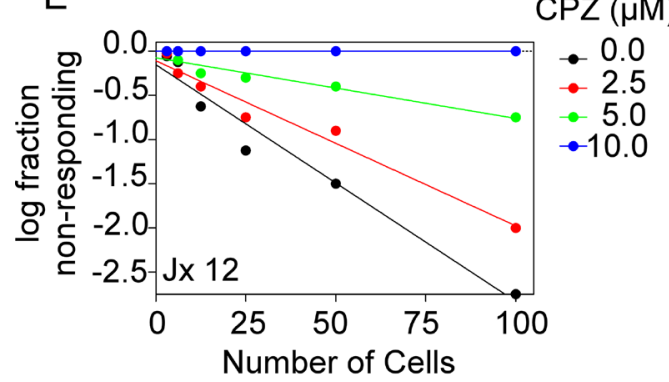

\begin{tabular}{|c|c|}
\hline Condition & $\begin{array}{c}\mathbf{1 / ( S t e m ~ C e l l ~ F r e q u e n c y ) ~} \\
{[\mathbf{9 5 \%} \mathbf{~ C l}]}\end{array}$ \\
\hline Control & $28.7[22.8-36.0]$ \\
\hline $2.5 \mu \mathrm{M} \mathrm{CPZ}$ & $49.5[38.8-63.1]$ \\
\hline $5 \mu \mathrm{M} \mathrm{CPZ}$ & $109.4[81-147.8]$ \\
\hline
\end{tabular}

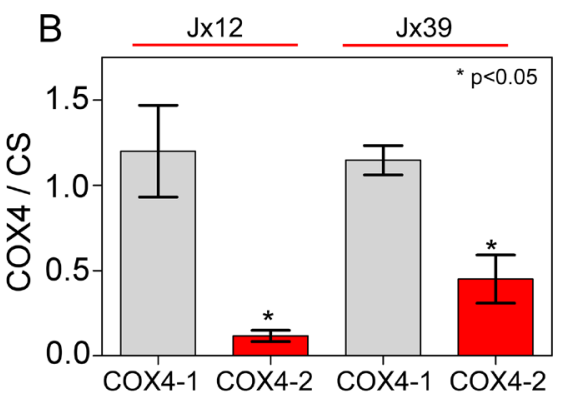

D

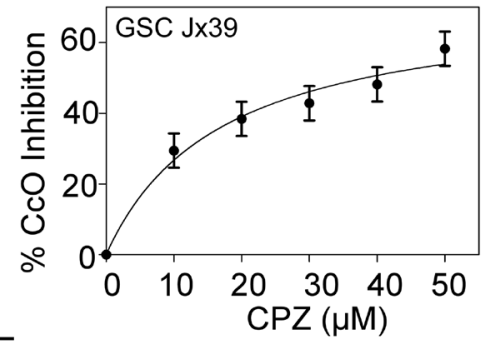

$\mathrm{F} \quad \mathrm{CPZ}(\mu \mathrm{M})$

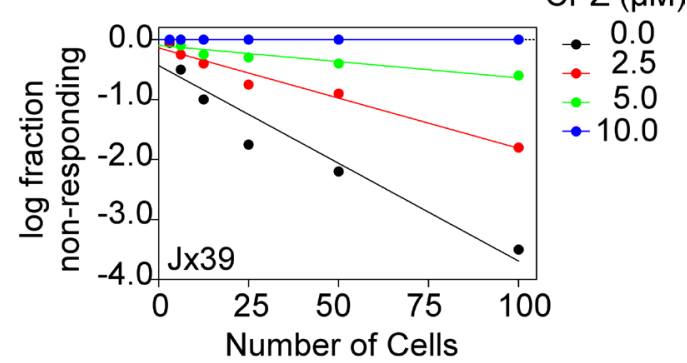

\begin{tabular}{|c|c|}
\hline Condition & $\begin{array}{c}1 /(\text { Stem Cell Frequency) } \\
{[\mathbf{9 5 \%} \mathbf{~ C l}]}\end{array}$ \\
\hline Control & $22.0[14.0-17.5]$ \\
\hline $2.5 \mu \mathrm{M} \mathrm{CPZ}$ & $49.1[38.6-62.6]$ \\
\hline $5 \mu \mathrm{M} \mathrm{CPZ}$ & $131.8[95.6-181.8]$ \\
\hline
\end{tabular}

Figure 4: Effects of CPZ on GSCs from human xenografts. (A) Representative Western blot showing the relative expression levels of endogenous COX4-1 and COX4-2 isoforms isolated from mitochondrial fractions of GSCs from $\mathrm{J} \times 12$ and $\mathrm{J} \times 39 \mathrm{xenolines}$. (B) Quantitative analysis of expression levels of COX4-1 and COX4-2 isoforms relative to citrate synthase (CS; loading control). Bars represent the average from duplicate determinations $\left({ }^{*} p<0.05\right)$. C,D. The effect of CPZ on the activity of CcO (complex IV), specifically, was tested in mitochondrial extracts from $\mathrm{J} \times 12(\mathbf{C})$ and $\mathrm{J} \times 39$ (D) xenolines. Graphs represent the level at which $\mathrm{CcO}$ activity is inhibited in the presence of $0 \mu \mathrm{M} \mathrm{CPZ}$ (control) or up to $50 \mu \mathrm{M} \mathrm{CPZ}$. The results are averages from triplicate determinations from two independent experiments. (E, F) In vitro limiting dilution assays (top panels) and quantification of GSCs (bottom panels) from $\mathrm{J} \times 12(\mathrm{E})$ and $\mathrm{J} \times 39(\mathrm{~F})$ xenolines treated with $\mathrm{CPZ}$ at the concentrations indicated. Results represent the average from two independent experiments. 
control-treated cells to $83.5 \%$ in cells treated with $20 \mu \mathrm{M}$ CPZ $(p=0.0072)$.

\section{$\mathrm{CPZ}$ inhibits $\mathrm{CcO}$ activity from bovine heart}

Because CPZ was tested using mitochondrial extracts from glioma cells, we assessed the possibility that the resulting $\mathrm{CcO}$ inhibition was an indirect effect due to binding to other mitochondrial components by evaluating the effect of $\mathrm{CPZ}$ on $\mathrm{CcO}$ purified from bovine heart. When evaluated by SDS-PAGE, the purified $\mathrm{CcO}$ enzymes produced multiple bands of apparent molecular mass ranging from 12 to $45 \mathrm{kDa}$ (Figure 6A). Western blot analysis demonstrated that COX4-1 was the most abundant COX4 isoform expressed (Figure 6B), with expression levels about 20-fold higher than the levels of COX4-2 (Figure 6C). CPZ significantly decreased the activity of purified $\mathrm{CcO}$ in a dose-dependent manner (Figure 6D), with an $\mathrm{IC}_{50}$ of $25.82 \pm 3.75 \mu \mathrm{M}$ (Figure $6 \mathrm{E}$ ). These results demonstrate a direct interaction of $\mathrm{CPZ}$ with $\mathrm{CcO}$.

\section{CPZ prolongs the survival time of mice bearing TMZ-resistant glioma cells}

To study whether CPZ is effective in an orthotopic mouse models, we stereotactically injected TMZ-sensitive U251 and TMZ-resistant UTMZ tumor cells into the right caudate/putamen of nude mice. Western blot analysis demonstrated that COX4-1 was the most abundant COX4 isoform expressed in the TMZ-resistant cell line (UTMZ) (Figure 7A), with expression levels about 10-fold higher than the levels of COX4-2 (Figure 7B). In contrast, the TMZ-sensitive cell line (U251) expressed mostly the COX4-2 isoform. After tumor inoculation, the mice were randomly allocated into three groups of 10 mice each and treated with saline or CPZ at 5 or $7 \mathrm{mg} / \mathrm{kg}$, injected intraperitoneally three times a week for 2 weeks and 5 days after tumor implantation. Median survival of mice was 18.5 days in the saline group and increased to 22.5 days in the $5 \mathrm{mg} / \mathrm{kg} \mathrm{CPZ} \mathrm{group}(p=0.01)$ and 25.0 days in the $7 \mathrm{mg} / \mathrm{kg} \mathrm{CPZ}$ group $(p=0.0007)$ (Figure $7 \mathrm{C}$ ). In contrast, CPZ treatment of mice bearing U251 glioma cells provided no benefit in median survival as determined by log-rank test (Figure 7D). No differences in behavior or weight were observed between saline-treated and CPZtreated mice (data not shown).

\section{CPZ likely binds to a hydrophobic pocket formed by COX4 and COX1}

To explore the potential mechanism of $\mathrm{CPZ} / \mathrm{CcO}$ binding, we constructed human $\mathrm{CcO}$ homology models and conducted structural analysis and molecular docking studies. $\mathrm{CcO}$ is a large protein complex with 13 different subunits (Figure 8A). Homology models of human $\mathrm{CcO}$ were built based on a crystal structure of mouse $\mathrm{CcO}$. The residues in the mouse $\mathrm{CcO} \mathrm{COX} 4$ subunit are $82 \%$ identical to and $96 \%$ homologous to the residues of human COX $4-1$ and $46 \%$ identical to and $64 \%$ homologous to the residues in human $\mathrm{COX} 4-2$. As a comparison, the residues in human COX4-1 are 45\% identical to and 58\% homologous to residues in human COX4-2. Modeling

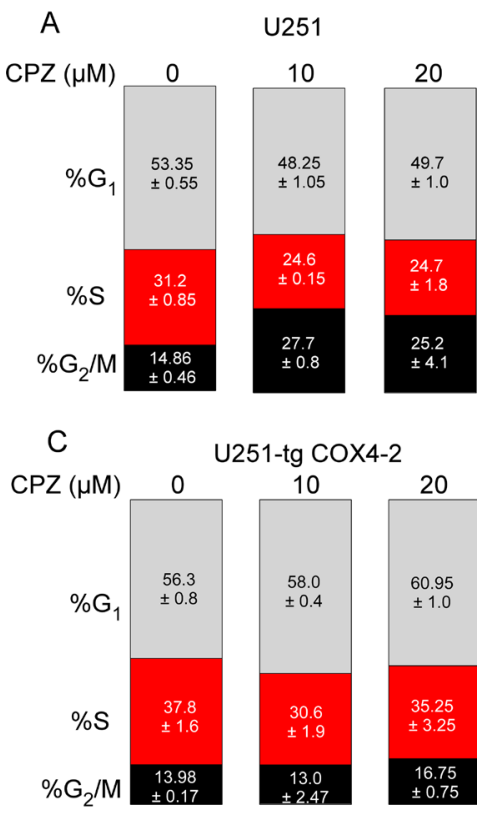

B

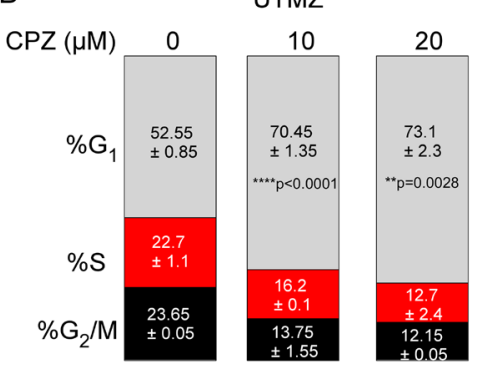

$\mathrm{D}$

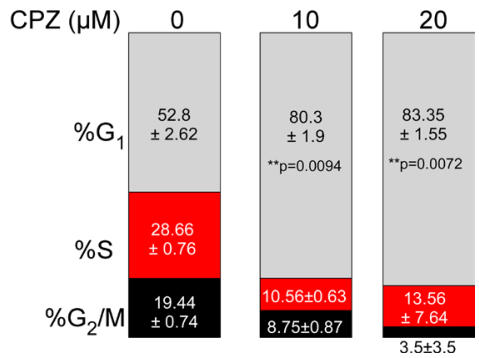

Figure 5: Effect of CPZ on cell cycle. (A-D) Average distributions of cells in G1, S, and G2/M phases for TMZ-sensitive U251 glioma cells (A), TMZ-resistant UTMZ glioma cells (B), and U251 glioma cells with CcO expressing COX4-2 (C) or COX4-1 (D). Cells were exposed to 0,10 , or $20 \mu \mathrm{M} \mathrm{CPZ}$ for $24 \mathrm{~h}$. Results represent the average from two independent experiments. 

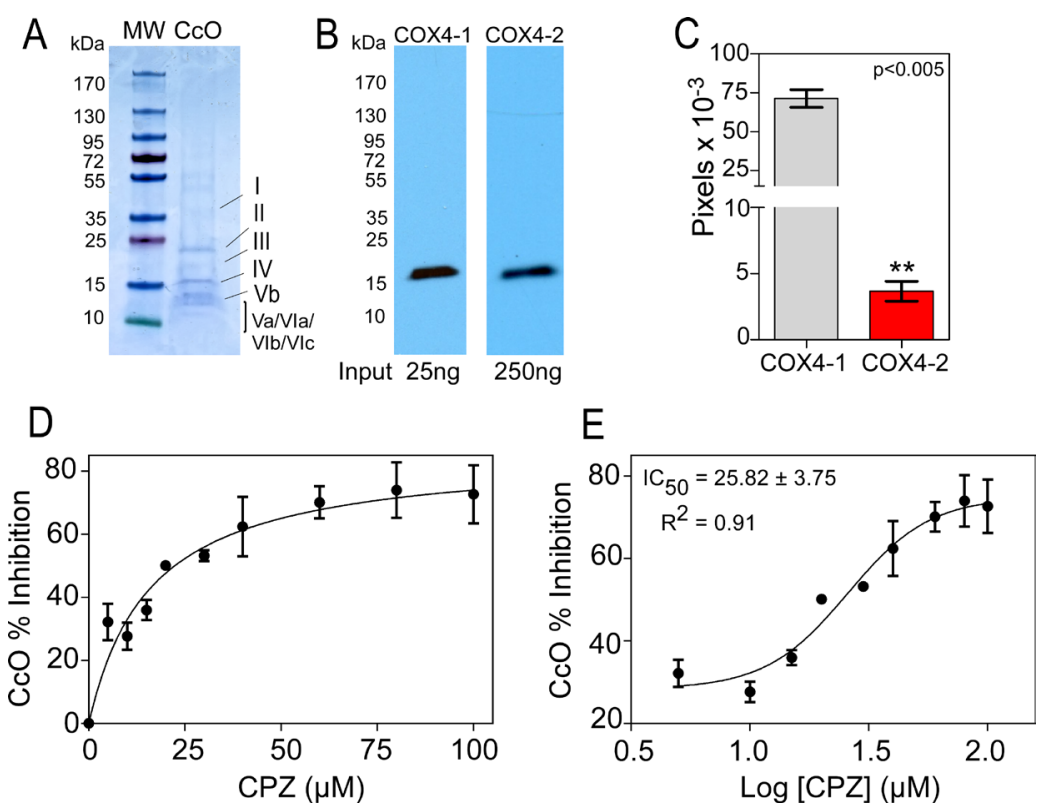

Figure 6: Effect of CPZ on CcO purified from bovine heart. (A) Representative SDS-PAGE stained with Coomassie blue. Lane 1, protein ladder. Lane 2, purified $\mathrm{CcO}$ from bovine heart $(5 \mu \mathrm{g})$. (B) Representative Western blot showing the expression of COX4-1 and COX4-2 isoforms in CcO purified from bovine heart. (C) Quantitative analysis of the relative expression levels of COX4-1 and COX4-2 isoforms in $\mathrm{CcO}$ from bovine heart. Bars represent the average from duplicate determinations. (D) Inhibition of CcO activity in the presence of $0 \mu \mathrm{M} \mathrm{CPZ}$ (control) and CPZ up to $100 \mu \mathrm{M}$. (E) Determination of $\mathrm{IC}_{50}$. The results are averages from triplicate determinations from two independent experiments.
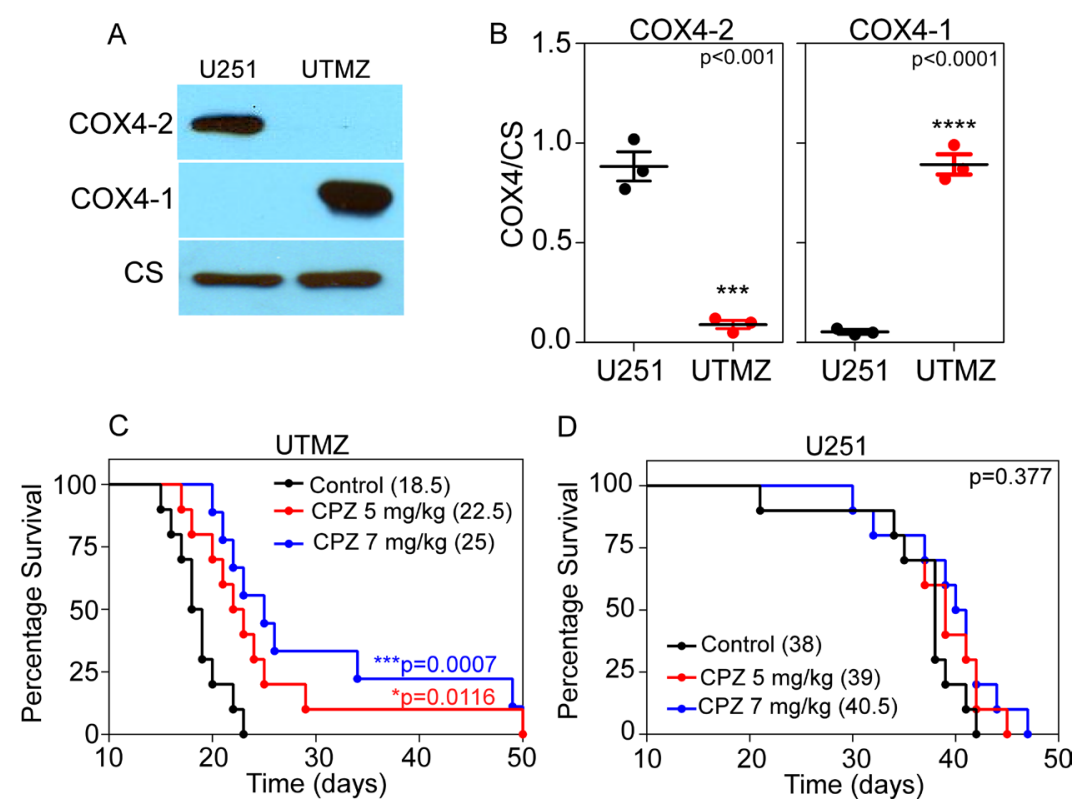

Figure 7: Survival data for CPZ-treated and untreated glioma-bearing mice. (A) Representative Western blot showing the expression of COX4-1 and COX4-2 isoforms in CcO from TMZ-resistant UTMZ or TMZ-sensitive U251 cells. (B) Quantitative analysis of the relative expression levels of COX4-1 and COX4-2 isoforms in CcO from U251 and UTMZ cells. Results represent the average from duplicate determinations. (C, D) TMZ-resistant UTMZ (C) or TMZ-sensitive U251 (D) glioma-bearing mice were treated with $\mathrm{CPZ}(5$ or $7 \mathrm{mg} / \mathrm{kg}$ ) or with saline (vehicle) as a control ( $n=10 \mathrm{mice} /$ group). In mice bearing UTMZ tumors, CPZ treatment significantly improved survival $(* * * p=0.0007$ versus saline). In mice bearing U251 tumors, there was no significant difference in survival between CPZ-treated and saline-treated controls $(p=0.377)$. 
showed that the COX4 subunit adopts a structure with a long helical middle fragment and two partly folded but mostly unstructured terminal ends (Figure 8B). Our structural mapping analysis indicated that the COX4 alone does not provide proper sites for ligand binding, but the $\mathrm{CcO}$ complex contains several potential binding sites that involve COX4 residues. Analysis of CPZ docking revealed one site as the most likely binding site for $\mathrm{CPZ}$ (Figure 8A and 8B). This identified site, which we named site A, is mainly a hydrophobic pocket and is formed by residues from the central helical region of $\mathrm{COX} 4$ and two other transmembrane helices of COX1 that are close to the HEME binding site. SiteA has an excellent SiteScore of 0.92 (a SiteScore value of 0.80 has been found to accurately distinguish between drug-binding and nondrug-binding sites [41]) and consists of residues that differ between COX4-1 and COX4-2, including Leu129/Lys131, Lys122/Arg124, Met119/Trp121, and Tyr126/Phe128 from COX4-1/COX4-2, respectively. The docked CPZ-COX4-1 model score $(-6.0 \mathrm{kcal} / \mathrm{mol})$ was significantly better than the score of the docked CPZ-COX4-2 model $(-5.3 \mathrm{kcal} /$ mol), suggesting $\mathrm{CPZ}$ binds more tightly to $\mathrm{CcO}$ with COX4-1 than to $\mathrm{CcO}$ with $\mathrm{COX} 4-2$. Such a result can be well explained by the different residues at siteA. The hydrophobic Leu129 makes the siteA of COX4-1 a partly closed pocket that is a more comfortable environment for CPZ binding; as a result, CPZ is able to form an H-bond with Lys122 and $\pi-\pi$ stacking interaction with the phenol ring of Tyr126 (Figure 8C). In contrast, the highly polar Lys131 of COX4-2 opens up the siteA, which makes the mainly hydrophobic CPZ molecule move toward the inner part of the pocket, and the relatively smaller sidechain of Phe128 (compared with Tyr126 of COX4-1) further permits such a movement. Additionally, the flat amide end of Arg124 (compared with Lys122 of COX4-1) impedes the formation of the H-bond, thus both the $\mathrm{H}$-bond and the $\pi-\pi$ stacking interaction are lost in the docked COX4-2 model (Figure 8D). Interestingly, in the $\mathrm{CcO}$ complex, COX11 locates very close to siteA, and in the docked COX4-1 model, the dimethylamine end of CPZ overlapped with residues of COX11 (Figure 8E). Therefore, CPZ binding would likely generate a steric hindrance that blocks the interactions between COX11 and the rest of the $\mathrm{CcO}$ complex, while the deeply buried $\mathrm{CPZ}$ identified in the COX4-2 model would not have such an effect (Figure 8E).

\section{DISCUSSION}

The Warburg effect, in which cells exhibit increases in glucose uptake, glycolytic capacity, and lactate production and the absence of respiration despite a high oxygen concentration, is often detected in tumor cells [3]. However, we and other groups have identified several glioma cell lines that are highly dependent on the mitochondrial OxPhos pathway to produce ATP [42-47].
Furthermore, we reported that a subclass of glioma cells that utilize glycolysis preferentially can also switch from aerobic glycolysis to OxPhos under limiting glucose conditions, as has been observed in cervical cancer cells, breast carcinoma cells, hepatoma cells, and pancreatic cancer cells as well [45-47]. Furthermore, a recent study demonstrated that mitochondrial ROS promote glioma progression [48]. Thus, targeting mitochondria could provide therapeutic opportunities.

In a retrospective clinical trial in patients with newly diagnosed primary GBM, we identified a subset of patients (25-30\% of the study population) with an extremely low overall survival (6 months) and high resistance to therapy [23]. Tumors in this population are characterized by less heterogeneity, OxPhos-dependent metabolism, elevated $\mathrm{CcO}$ activity, and enrichment in GSCs. Similar results from another research group identified patients with GBM characterized by low overall survival and tumors with upregulated expression levels of metabolic enzymes, including $\mathrm{CcO}$ [49]. We have also demonstrated that during tumor regrowth (recurrence), a switch from glycolytic to OxPhos metabolism may occur with a concomitant increase of $\mathrm{CcO}$ activity $[12,17]$. Additionally, we showed that genetic and pharmacologic inhibition of $\mathrm{CcO}$ activity suppresses tumor growth and depletes GSCs in gliomas, providing a strategic opportunity to improve therapeutic outcomes in patients with GBM $[12,17,50]$. With respect to this concept, we recently identified and characterized a novel small molecule inhibitor of CcO (ADDA 5) [50]. ADDA 5 inhibits the proliferation of glioma cells, without toxicity against non-cancer cells, and treatment with ADDA 5 significantly inhibits tumor growth in flank xenograft mouse models. Importantly, ADDA 5 inhibits $\mathrm{CcO}$ activity and blocks cell proliferation and neurosphere formation of GSCs [50].

However, while ADDA 5 is a promising compound for the treatment of GBM, clinical translation of this compound may take years. The repositioning of existing Food and Drug Administration (FDA)-approved drugs can bypass or shorten critical steps of drug development, such as chemical optimization and toxicology testing, thereby resulting in a shorter time frame for clinical translation and patient benefits. We propose that FDA-approved agents that cross the blood brain barrier, such as CPZ, can be repurposed for use in the treatment of chemoresistant GBM.

Although CPZ-mediated blockade of $\mathrm{CcO}$ activity was described $>50$ years ago [39], the effects of CPZ on mitochondrial ETC complexes specifically in glioma cells were not examined. Our study of these effects revealed that CPZ does not affect complexes I, II-III, or V. Notably, $\mathrm{CPZ}$ did significantly decrease $\mathrm{CcO}$ activity, but only in TMZ-resistant glioma cells. We previously showed that acquisition of TMZ-resistance is associated with a switch in the regulatory subunit of $\mathrm{CcO}$ such that the $\mathrm{COX} 4-1$ isoform, rather than the COX4-2 isoform, is mainly expressed [12]. To determine if the expression of COX4-1 
underlies the specificity of CPZ for TMZ-resistant cells, we compared the effects of $\mathrm{CPZ}$ on $\mathrm{CcO}$ from glioma cells expressing COX4-1 and from cells expressing COX4-2 [11]. CPZ inhibited CcO activity only when the COX4-1 subunit was expressed, suggesting that the COX4 isoform-specific differences in $\mathrm{CcO}$ structure control the interaction with CPZ.

Analysis of the mechanism of inhibition showed that $\mathrm{CPZ}$ is a non-competitive inhibitor of $\mathrm{CcO}$ with respect to the cyt c substrate, providing strong evidence that $\mathrm{CPZ}$ binds to an allosteric site rather than to the active site of cyt c. Of note, it was previously shown that CPZ blocks $\mathrm{CcO}$ activity by a competitive mechanism that blocks the interaction with cyt c $[39,40]$. The discrepancy with our results may be due to cell type-specific responses, differences in normal and cancer cells, or variations in experimental conditions. Specifically, the results reported by Dawkins et al. [39] reflect the effect of CPZ on the activity of $\mathrm{CcO}$ from normal liver mitochondria, whereas our study characterized the effect of $\mathrm{CPZ}$ on $\mathrm{CcO}$ from human brain cancer cells. Furthermore, the concentrations of CPZ which they found necessary to inhibit $\mathrm{CcO}$ activity were significantly higher than the one reported here
(150-200 $\mu \mathrm{M}$ vs 10-30 $\mu \mathrm{M}$ ), which may be a consequence of the high concentrations of cyt c tested in their system (30-200 $\mu \mathrm{M})$.

Our computer modeling studies suggested that CPZ binds to a hydrophobic pocket formed by residues from the central helical region of $\mathrm{COX} 4$ and two other transmembrane helices of COX1 that are close to the HEME binding site. Our docking studies also suggested that $\mathrm{CPZ}$ binds more favorably to $\mathrm{CcO}$ with $\mathrm{COX} 4-1$ than with $\mathrm{COX} 4-2$, and may affect $\mathrm{CcO}$ function through direct interactions with COX1 residues that are close to the HEME center, by preventing the recruitment of COX11, or through a combination of these mechanisms.

In vitro, $\mathrm{CPZ}$ inhibited cell proliferation and anchorage-independent growth in chemoresistant but not chemosensitive glioma cells. CPZ also inhibited cell proliferation of GSCs. These data suggest that CPZ would be effective in minimizing recurrence that may result from the proliferation and differentiation of GSCs.

Our results showed that the growth inhibition is achieved at a concentration of CPZ between 1 and $15 \mu \mathrm{M}$. Since we evaluated different cellular processes (attached cell growth and anchorage-independent

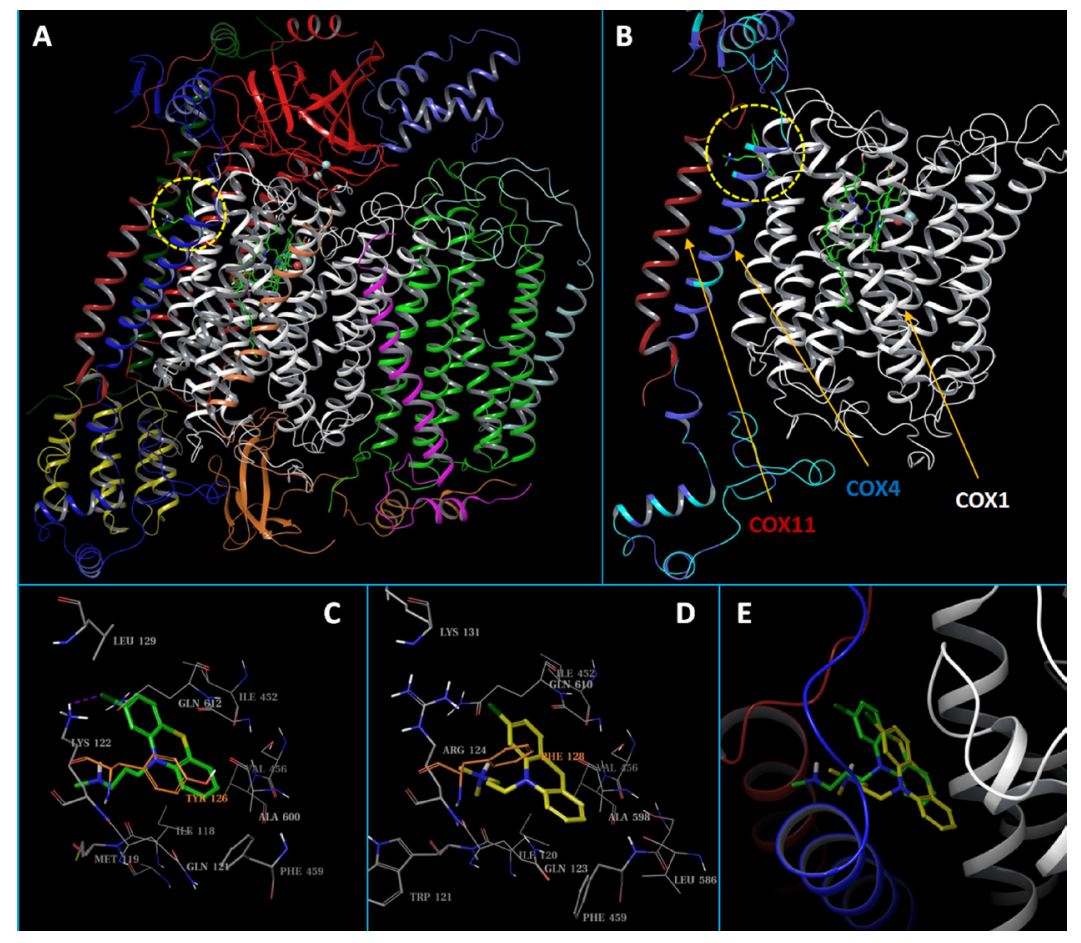

Figure 8: Structural presentation of the predicted binding modes of CPZ to human CcO. (A) Carton presentation of the $\mathrm{CcO}$ complex model with each of its 13 subunits shown in differently colored ribbons. The predicted binding site, site $\mathrm{A}$, was circled in a dashed yellow line. (B) CcO subunits that are close to siteA. The HEME molecule and the docked CPZ molecule are shown in solid sticks. COX1 and COX11 are shown in white and red ribbons, respectively. For the COX4 ribbon, residues that are the same between COX4-1 and COX4-2 were colored in blue, while residues that are different are colored in cyan. (C and D) Close up view of the binding site interactions of the docked CPZ in the COX4-1 and the COX4-2 models, respectively. The CPZ molecules are shown in solid sticks and colored in green and yellow, respectively. Binding site residues are shown in gray lines. The key and non-conserved residues are shown in thin sticks, or colored in orange. (E) Overlaid docked CPZ molecules from the COX4-1 and COX4-2 models. CPZs and CcO ribbons are colored the same as above. 
cell growth), it is absolutely possible that both processes are differentially affected by CPZ. Indeed, the concentration necessary to block $\mathrm{CcO}$ activity in vitro is significantly higher $\left(\mathrm{IC}_{50}=30 \mu \mathrm{M}\right)$. It is possible that the mitochondrial membrane potential can increase uptake and/or prolong retention of $\mathrm{CPZ}$ within the mitochondria, reducing the $\mathrm{IC}_{50}$ in intact cells.

Notably, CPZ treatment substantially increased the survival of mice bearing intracranial TMZ-resistant glioma cells, without any noticeable adverse effects such as change in animal weight or behavior, implying a potential therapeutic application for CPZ.

$\mathrm{CcO}$ is widely expressed in mitochondria of eukaryotes, which raises concern about systemic inhibition of $\mathrm{CcO}$. However, mitochondria have emerged recently as effective targets for novel anti-cancer drugs with high specificity for cancer cells [50-63]. Indeed, we have identified the molecular mechanisms that permit the malignant cell-selectivity of inhibitors of CcO. Normal mammalian cells have a relatively large excess (3- to 10-fold) of $\mathrm{CcO}$ activity compared with that in primary and recurrent GBM [64-69]. In normal brain cells, therefore, the $\mathrm{CcO}$ activity could be decreased by approximately $70 \%$ before major changes in mitochondrial respiration and ATP synthesis occur $[64,65]$, whereas a $7-22 \%$ decrease in $\mathrm{CcO}$ activity is sufficient to promote the alteration of energy homeostasis in malignant cells $[12,69]$. Thus, the higher $\mathrm{CcO}$ activity and threshold in respiration in normal cells offers a window for the therapeutic use of $\mathrm{CcO}$-specific inhibitors, since the doses necessary to effectively decrease $\mathrm{CcO}$ activity in malignant cells should not affect the overall capability of $\mathrm{CcO}$ to maintain energy homeostasis in normal cells.

Furthermore, we demonstrated that CPZ blocks proliferation of chemoresistant gliomas. Interestingly, cell cycle analyses showed that the decreased proliferative activity is due to cell cycle arrest, rather than increased apoptosis. Indeed, we detected few apoptotic cells and the number did not significantly increase throughout CPZ treatment (data not shown). $\mathrm{CPZ}$ has also been shown to inhibit cell-cycle progression in rat glioma C6 cells by inducing p21 Waf/ Cip1/Egr1 expression [36] and to induce autophagic cell death by inhibiting the AKT/mTOR pathway in human glioma U87-MG cells [37]. In addition, CPZ enhanced therapeutic efficacy in tamoxifen-resistant breast cancer cells [38] and in colorectal cancer [34], suggesting this drug as a potential agent for improving the efficacy of cancer chemotherapy.

In conclusion, our study provides new insight into the repositioning of $\mathrm{CPZ}$ for the treatment of chemoresistant gliomas. Future studies should investigate the potential interactions between $\mathrm{CPZ}$ and other conventional anti-GBM therapies.

\section{MATERIALS AND METHODS}

\section{Cell culture}

TMZ-sensitive U251 cells and TMZ-resistant cells derived from U251 cells (UTMZ) were grown in DMEM F-12 medium plus l-glutamine supplemented with 7\% heat-inactivated FBS, penicillin, and streptomycin as we previously described $[11,12,17,42,50,55,70,71]$. The resistant cell line was obtained by progressive adaptation of the parental sensitive cells (U251) to increasing concentrations of TMZ [12]. FLAG-epitope-tagged COX4-2 and COX4-1 were generated and transfected into U251 cells stably depleted of the endogenously expressed COX4-2, as previously described [11].

Cell lines are grown continuously up to 10 passages, and then we start a new culture from frozen seed stocks. Cell lines are regularly tested for mycoplasma contamination using the Universal Mycoplasma Detection kit (ATCC $\left.{ }^{\circledR} 30-1012 \mathrm{KTM}\right)$ and authenticated by the ATCC authentication service utilizing short tandem repeat (STR) profiling.

\section{Cell proliferation assay}

For cell proliferation, glioma cells were seeded into 24 -well plates $\left(3 \times 10^{4}\right.$ cells/well), and cell number was counted every $24 \mathrm{~h}$ for 4 days as previously described [11].

\section{Soft agar growth assay}

A bottom layer of $0.4 \%$ agarose and DMEM/ F12 with 10\% FBS was poured and allowed to solidify. Additional agarose was allowed to reach $42^{\circ} \mathrm{C}$ and then $7.5 \times 10^{3}$ tumor cells were added to the agarose/media solution and poured onto the bottom layer. Appropriate concentrations of $\mathrm{CPZ}$ were added to both agarose/ media layers. Cells were incubated at $37^{\circ} \mathrm{C}$ for 4 weeks to form colonies, followed by staining with $0.005 \%$ crystal violet. The colonies were imaged and quantified using the Gel Dock imager and Quantity One software (BioRad).

\section{In vitro limiting dilution assay}

In vitro dilution assays were performed as previously described [11]. Briefly, single-cell suspensions were plated at 1,2,5,10,20, and 40 cells per well in 96-well plates in neurobasal medium containing EGF and FGF. Ten days after plating, the number of neurospheres in each well and the percentage of positive wells were quantified by manual counting. Extreme limiting dilution assay analyses were performed on the data as previously described [11, 44, 45]. 


\section{Primary GBM xenograft lines}

The establishment and maintenance of the Mayo GBM xenograft lines $\mathrm{J} \times 12$ and $\mathrm{J} \times 39$ has been described $[12,17,72-76] . \mathrm{J} \times 12$ and $\mathrm{J} \times 39$ are classical subtype patient-derived GBM xenograft cell lines (xenolines) that were established in immunocompromised athymic nude mice from surgical resection waste specimens obtained from consented patients undergoing surgical therapy for primary GBM. All animal studies were approved by the UAB Institutional Animal Care and Use Committee at the University of Alabama at Birmingham.

\section{Intracranial tumors}

All surgical and experimental procedures and animal care were performed in accordance and compliance with the policies approved by the University of Alabama at Birmingham Institutional Animal Care and Use Committee (APN 131209529) as we previously described (11). Briefly, intracranial gliomas were generated using $3 \times 10^{5} \mathrm{U} 251$ or UTMZ human glioma cells suspended in $5 \%$ methylcellulose in serum-free medium. The cells were drawn into a $250-\mu 1$ Hamilton gas-tight syringe mounted in a Chaney repeating dispenser and fitted with a $30 \mathrm{G} 1 / 2$-inch needle with a calibrated depth of $2.5 \mathrm{~mm}$ from the middle of the bevel opening. Under an operating microscope, the fascia on the skull of the anesthetized mouse was scraped off and a $0.5-\mathrm{mm}$ burr hole was made $2 \mathrm{~mm}$ to the right of the midline suture and $1 \mathrm{~mm}$ caudal to the coronal suture. The syringe was inserted into a Kopf stereotactic electrode clamp mounting bracket attached to an electrode manipulator (David Kopf Instruments; Tujinga, CA) mounted on a Kopf stereotactic frame electrode A-P zeroing bar (\#1450). Each mouse was positioned on the stereotactic frame and the needle inserted to the depth marker in the right cerebral hemisphere. Approximately 90-120 sec after injection of $5 \mu 1$, the needle was slowly withdrawn over the next $1 \mathrm{~min}$. The burr hole was plugged with sterile bone wax and skin was closed with Tissumend surgical adhesive (Stryker Orthopedics; Kalamazoo, MI). The major endpoint in this study was animal survival; moribund animals that became unresponsive to mild external stimuli were euthanized and this date was used as an estimate of the date of death.

\section{Preparation of mitochondria and mitochondrial complex activities}

Mitochondria were prepared according to Higuchi and Linn (42). Briefly, cells were washed twice in PBS. The pellet was resuspended in magnesium resuspension buffer (MgRSB; $10 \mathrm{mM} \mathrm{NaCl}, 1.5 \mathrm{mM} \mathrm{MgCl}, 10 \mathrm{mM}$ Tris- $\mathrm{HCl}, \mathrm{pH} 7.5$ ), incubated at $4^{\circ} \mathrm{C}$ for $10 \mathrm{~min}$, and then disrupted with a Dounce glass homogenizer. The homogenate was diluted with 1.3 volumes of mannitol- sucrose buffer (MSB; $0.525 \mathrm{mM}$ mannitol, $175 \mathrm{mM}$ sucrose, $12.5 \mathrm{mM}$ EDTA, $12.5 \mathrm{mM}$ Tris- $\mathrm{HCl}, \mathrm{pH} 7.5$ ) and centrifuged at $1000 \times \mathrm{g}$ for $10 \mathrm{~min}$ to remove cell debris. The supernatant was further centrifuged at $20,000 \times \mathrm{g}$ for $20 \mathrm{~min}$. The mitochondrial pellets were then digested with DNase I (Sigma-Aldrich) at $37^{\circ} \mathrm{C}$ for $30 \mathrm{~min}$ to digest nuclear DNA. After digestion, the mitochondrial pellets were washed three times with MSB, deep-frozen in liquid nitrogen, and stored at $-80^{\circ} \mathrm{C}$.

Mitochondrial complex activities and kinetic parameters for $\mathrm{CcO}$ activity were determined as previously described [50]. Purified $\mathrm{CcO}$ from bovine heart was acquired from Sigma-Aldrich (catalog \# C5499, lot \# $036 \mathrm{M} 4111 \mathrm{~V}$ ). The purity and the identity of each band was confirmed by MS-based analysis [50, 77].

\section{Western blot analysis}

Western blot analysis was performed as we previously described $(11,12)$. The following antibodies were used: anti-citrate synthase (1:1000 dilution, 161311-AP, ProteinTech Group, Chicago, IL); anti-COX4-1 (1:1000 dilution, ab14744, Abcam, Cambridge, MA), and anti-COX4-2 (1:1000 dilution, 11463-1-AP, ProteinTech Group). Anti-COX4-1 and anti-COX4-2 antibodies were tested for specificity, and no cross-reactivity between isoforms was detected.

\section{Cell cycle analysis}

Cell cycle analysis was performed as we previously described (45). Briefly, glioma cells were cultured in 6-well plates and synchronized for $48 \mathrm{~h}$ in normal DMEM/F12 serum-free medium. After $48 \mathrm{~h}$, serum-free medium was replaced by DMEM/F12 medium supplemented with 7\% serum with or without graded concentrations of $\mathrm{CPZ}$ for $24 \mathrm{~h}$. Then, cells were collected and pellets resuspended in $70 \%$ cold ethanol for up to $18 \mathrm{~h}$. Fixed cells were pelleted by centrifugation and treated ( $20 \mathrm{~min}$, room temperature) with $100 \mathrm{U}$ of DNase-free RNase A/10 $0^{6}$ cells. Nuclei were stained with $500 \mu \mathrm{l}$ of propidium iodide $(20 \mu \mathrm{g} / \mathrm{ml})$ before nuclear DNA content was analyzed by flow cytometry using a BD Accuri' ${ }^{\mathrm{TM}}$ C6 flow cytometer. All data were acquired and analyzed using FlowJo software.

\section{Molecular modeling}

Structural model generation and molecular docking studies were conducted using the programs of the Schrödinger Suite 2015 (Schrödinger, LLC, New York, NY, 2015). Based on the crystal structures of mouse $\mathrm{CcO}$ (Protein Data Bank ID: 2Y69) [78], two human $\mathrm{CcO}$ homology models were constructed for COX4-1 and COX4-2 using the Prime program. Potential ligand binding sites were identified based on structural analysis of the $\mathrm{CcO}$ models using the SiteMap program. The three- 
dimensional structure of CPZ was prepared using the LigPrep program and the docking studies were conducted with the Glide program. Specifically, the induced-fitdocking (IFD) protocol [79], which is capable of sampling dramatic side-chain conformational changes as well as minor changes in protein backbone structure, was applied to explore the modes of CPZ binding at different binding sites. Residues within $5 \AA$ of the docked $\mathrm{CPZ}$ were allowed to be flexible and the docked results were scored using the extra-precision (XP) mode of Glide.

\section{Statistics}

Data were evaluated using GraphPad. All reported $p$ values are two-sided $t$-test, and $p$ values $<0.05$ were considered to indicate statistical significance. Experiments were performed in triplicate and were performed twice or more to verify the results. Data are shown as the means \pm S.D. $p<0.05(*), p<0.01(* *), p<0.001(* * *)$ and $p<0.0001(* * * *)$.

\section{Authors' contributions}

CEG and CRO have contributed equally to this work. CL, WS and MJS performed molecular modeling studies.

\section{ACKNOWLEDGMENTS}

The authors acknowledge the members of the Brain Tumor Animal Models Core for their assistance. The authors would like to thank Dr. Erin Thacker for the professional editing of the manuscript.

\section{CONFLICTS OF INTEREST}

Authors declare no potential conflicts of interest.

\section{GRANT SUPPORT}

Research reported in this publication was supported in part by National Institutes of Health Grants R01 CA127716 and P20CA151129. The content is solely the responsibility of the authors and does not necessarily represent the official views of the National Institutes of Health.

\section{REFERENCES}

1. Stupp R, Mason WP, van den Bent MJ, Weller M, Fisher B, Taphoorn MJ, Belanger K, Brandes AA, Marosi C, Bogdahn U, Curschmann J, Janzer RC, Ludwin SK, et al, and European Organisation for Research and Treatment of Cancer Brain Tumor and Radiotherapy Groups, and National Cancer Institute of Canada Clinical Trials Group.
Radiotherapy plus concomitant and adjuvant temozolomide for glioblastoma. N Engl J Med. 2005; 352:987-96.

2. Stupp R, van den Bent MJ, Hegi ME. Optimal role of temozolomide in the treatment of malignant gliomas. Curr Neurol Neurosci Rep. 2005; 5:198-206.

3. Devic S. Warburg Effect - a Consequence or the Cause of Carcinogenesis? J Cancer. 2016; 7:817-22.

4. Sancho P, Barneda D, Heeschen C. Hallmarks of cancer stem cell metabolism. Br J Cancer. 2016; 114:1305-12.

5. Dong C, Yuan T, Wu Y, Wang Y, Fan TW, Miriyala S, Lin Y, Yao J, Shi J, Kang T, Lorkiewicz P, St Clair D, Hung MC, et al. Loss of FBP1 by Snail-mediated repression provides metabolic advantages in basal-like breast cancer. Cancer Cell. 2013; 23:316-31.

6. Shen YA, Wang CY, Hsieh YT, Chen YJ, Wei YH. Metabolic reprogramming orchestrates cancer stem cell properties in nasopharyngeal carcinoma. Cell Cycle. 2015; 14:86-98.

7. Chen CL, Uthaya Kumar DB, Punj V, Xu J, Sher L, Tahara SM, Hess S, Machida K. NANOG Metabolically Reprograms Tumor-Initiating Stem-like Cells through Tumorigenic Changes in Oxidative Phosphorylation and Fatty Acid Metabolism. Cell Metab. 2016; 23:206-19.

8. Gao C, Shen Y, Jin F, Miao Y, Qiu X. Cancer Stem Cells in Small Cell Lung Cancer Cell Line H446: Higher Dependency on Oxidative Phosphorylation and Mitochondrial Substrate-Level Phosphorylation than NonStem Cancer Cells. PLoS One. 2016; 11:e0154576.

9. Ye XQ, Li Q, Wang GH, Sun FF, Huang GJ, Bian XW, Yu SC, Qian GS. Mitochondrial and energy metabolism-related properties as novel indicators of lung cancer stem cells. Int J Cancer. 2011; 129:820-31.

10. Janiszewska M, Suvà ML, Riggi N, Houtkooper RH, Auwerx J, Clément-Schatlo V, Radovanovic I, Rheinbay E, Provero P, Stamenkovic I. Imp2 controls oxidative phosphorylation and is crucial for preserving glioblastoma cancer stem cells. Genes Dev. 2012; 26:1926-44.

11. Oliva CR, Markert T, Gillespie GY, Griguer CE. Nuclearencoded cytochrome c oxidase subunit 4 regulates BMI1 expression and determines proliferative capacity of highgrade gliomas. Oncotarget. 2015; 6:4330-44. doi: 10.18632/ oncotarget.3015

12. Oliva CR, Nozell SE, Diers A, McClugage SG 3rd, Sarkaria JN, Markert JM, Darley-Usmar VM, Bailey SM, Gillespie GY, Landar A, Griguer CE. Acquisition of temozolomide chemoresistance in gliomas leads to remodeling of mitochondrial electron transport chain. J Biol Chem. 2010; 285:39759-67.

13. Sancho P, Burgos-Ramos E, Tavera A, Bou Kheir T, Jagust P, Schoenhals M, Barneda D, Sellers K, Campos-Olivas R, Graña O, Viera CR, Yuneva M, Sainz B Jr, et al. MYC/ PGC-1 $\alpha$ Balance Determines the Metabolic Phenotype and Plasticity of Pancreatic Cancer Stem Cells. Cell Metab. $2015 ; 22: 590-605$. 
14. Lagadinou ED, Sach A, Callahan K, Rossi RM, Neering SJ, Minhajuddin M, Ashton JM, Pei S, Grose V, O’Dwyer KM, Liesveld JL, Brookes PS, Becker MW, et al. BCL-2 inhibition targets oxidative phosphorylation and selectively eradicates quiescent human leukemia stem cells. Cell Stem Cell. 2013; 12:329-41.

15. Grossman LI, Lomax MI. Nuclear genes for cytochrome $\mathrm{c}$ oxidase. Biochim Biophys Acta. 1997; 1352:174-92.

16. Kadenbach B, Hüttemann M, Arnold S, Lee I, Bender E. Mitochondrial energy metabolism is regulated via nuclearcoded subunits of cytochrome c oxidase. Free Radic Biol Med. 2000; 29:211-21.

17. Oliva CR, Moellering DR, Gillespie GY, Griguer CE. Acquisition of chemoresistance in gliomas is associated with increased mitochondrial coupling and decreased ROS production. PLoS One. 2011; 6:e24665.

18. Campian JL, Gao X, Qian M, Eaton JW. Cytochrome C oxidase activity and oxygen tolerance. J Biol Chem. 2007; 282:12430-38.

19. Seelan RS, Grossman LI. Structural organization and promoter analysis of the bovine cytochrome c oxidase subunit VIIc gene. A functional role for YY1. J Biol Chem. 1997; 272:10175-81.

20. Chen WL, Kuo KT, Chou TY, Chen CL, Wang CH, Wei YH, Wang LS. The role of cytochrome c oxidase subunit Va in non-small cell lung carcinoma cells: association with migration, invasion and prediction of distant metastasis. BMC Cancer. 2012; 12:273.

21. Liang L, Qu L, Ding Y. Protein and mRNA characterization in human colorectal carcinoma cell lines with different metastatic potentials. Cancer Invest. 2007; 25:427-34.

22. Kadenbach B, Hüttemann M. The subunit composition and function of mammalian cytochrome c oxidase. Mitochondrion. 2015; 24:64-76.

23. Griguer CE, Cantor AB, Fathallah-Shaykh HM, Gillespie GY, Gordon AS, Markert JM, Radovanovic I, ClementSchatlo V, Shannon CN, Oliva CR. Prognostic relevance of cytochrome $\mathrm{C}$ oxidase in primary glioblastoma multiforme. PLoS One. 2013; 8:e61035.

24. Napiwotzki J, Shinzawa-Itoh K, Yoshikawa S, Kadenbach B. ATP and ADP bind to cytochrome c oxidase and regulate its activity. Biol Chem. 1997; 378:1013-21.

25. Acin-Perez R, Gatti DL, Bai Y, Manfredi G. Protein phosphorylation and prevention of cytochrome oxidase inhibition by ATP: coupled mechanisms of energy metabolism regulation. Cell Metab. 2011; 13:712-19.

26. Arnold S, Kadenbach B. The intramitochondrial ATP/ADPratio controls cytochrome c oxidase activity allosterically. FEBS Lett. 1999; 443:105-08.

27. Hüttemann M, Lee I, Gao X, Pecina P, Pecinova A, Liu J, Aras S, Sommer N, Sanderson TH, Tost M, Neff F, AguilarPimentel JA, Becker L, et al. Cytochrome c oxidase subunit 4 isoform 2-knockout mice show reduced enzyme activity, airway hyporeactivity, and lung pathology. FASEB J. 2012; 26:3916-30.
28. Landriscina M, Maddalena F, Laudiero G, Esposito F. Adaptation to oxidative stress, chemoresistance, and cell survival. Antioxid Redox Signal. 2009; 11:2701-2716.

29. Goodman LS, Hardman JG, Limbird LE, Gilman AG. (1996). Goodman \& Gilman's the pharmacological basis of therapeutics. New York: McGraw-Hill, Medical Pub Division.

30. Saha KB, Bo L, Zhao S, Xia J, Sampson S, Zaman RU. Chlorpromazine versus atypical antipsychotic drugs for schizophrenia. Cochrane Database Syst Rev. 2016; 4:CD010631.

31. WHO. WHO Model List of Essential Medicines. 18th ed. World Health Organization; 2013.

32. Fujita K, Iwase S, Ito T, Matsuyama M. Inhibiting effect of chlorpromazine on the experimental production of liver cancer. Nature. 1958; 181:54.

33. Lee MS, Johansen L, Zhang Y, Wilson A, Keegan M, Avery W, Elliott P, Borisy AA, Keith CT. The novel combination of chlorpromazine and pentamidine exerts synergistic antiproliferative effects through dual mitotic action. Cancer Res. 2007; 67:11359-67.

34. Lee WY, Lee WT, Cheng CH, Chen KC, Chou CM, Chung $\mathrm{CH}$, Sun MS, Cheng HW, Ho MN, Lin CW. Repositioning antipsychotic chlorpromazine for treating colorectal cancer by inhibiting sirtuin 1 . Oncotarget. 2015; 6:27580-95. doi: 10.18632/oncotarget.4768

35. Lialiaris TS, Papachristou F, Mourelatos C, Simopoulou M. Antineoplastic and cytogenetic effects of chlorpromazine on human lymphocytes in vitro and on Ehrlich ascites tumor cells in vivo. Anticancer Drugs. 2009; 20:746-51.

36. Shin SY, Kim CG, Kim SH, Kim YS, Lim Y, Lee YH. Chlorpromazine activates p21Waf1/Cip1 gene transcription via early growth response-1 (Egr-1) in C6 glioma cells. Exp Mol Med. 2010; 42:395-405.

37. Shin SY, Lee KS, Choi YK, Lim HJ, Lee HG, Lim Y, Lee YH. The antipsychotic agent chlorpromazine induces autophagic cell death by inhibiting the Akt/mTOR pathway in human U-87MG glioma cells. Carcinogenesis. 2013; 34:2080-89.

38. Yde CW, Clausen MP, Bennetzen MV, Lykkesfeldt AE, Mouritsen OG, Guerra B. The antipsychotic drug chlorpromazine enhances the cytotoxic effect of tamoxifen in tamoxifen-sensitive and tamoxifen-resistant human breast cancer cells. Anticancer Drugs. 2009; 20:723-35.

39. Dawkins MJ, Judah JD, Rees KR. The effect of chlorpromazine on the respiratory chain; cytochrome oxidase. Biochem J. 1959; 72:204-09.

40. Dawkins MJ, Judah JD, Rees KR. The mechanism of action of chlorpromazine. Reduced diphosphopyridine nucleotidecytochrome c reductase and coupled phosphorylation. Biochem J. 1959; 73:16-23.

41. SiteMap v, Schrödinger, LLC, New York, NY, 2015.

42. Griguer CE, Oliva CR, Gillespie GY. Glucose metabolism heterogeneity in human and mouse malignant glioma cell lines. J Neurooncol. 2005; 74:123-33. 
43. Bouzier AK, Voisin P, Goodwin R, Canioni P, Merle M. Glucose and lactate metabolism in C6 glioma cells: evidence for the preferential utilization of lactate for cell oxidative metabolism. Dev Neurosci. 1998; 20:331-38.

44. Beckner ME, Gobbel GT, Abounader R, Burovic F, Agostino NR, Laterra J, Pollack IF. Glycolytic glioma cells with active glycogen synthase are sensitive to PTEN and inhibitors of PI3K and gluconeogenesis. Lab Invest. 2005; 85:1457-70.

45. Rossignol R, Gilkerson R, Aggeler R, Yamagata K, Remington SJ, Capaldi RA. Energy substrate modulates mitochondrial structure and oxidative capacity in cancer cells. Cancer Res. 2004; 64:985-93.

46. Smolková K, Bellance N, Scandurra F, Génot E, Gnaiger E, Plecitá-Hlavatá L, Jezek P, Rossignol R. Mitochondrial bioenergetic adaptations of breast cancer cells to aglycemia and hypoxia. J Bioenerg Biomembr. 2010; 42:55-67.

47. Plecita-Hlavata L, Lessard M, Santorova J, Bewersdorf J, Jezek P. Mitochondrial oxidative phosphorylation and energetic status are reflected by morphology of mitochondrial network in INS-1E and HEP-G2 cells viewed by 4Pi microscopy. Biochim Biophys Acta. 2008; 1777:834-846.

48. Yuan S, Lu Y, Yang J, Chen G, Kim S, Feng L, Ogasawara M, Hammoudi N, Lu W, Zhang H, Liu J, Colman H, Lee $\mathrm{JS}$, et al. Metabolic activation of mitochondria in glioma stem cells promotes cancer development through a reactive oxygen species-mediated mechanism. Stem Cell Res Ther. $2015 ; 6: 198$.

49. Haskins WE, Zablotsky BL, Foret MR, Ihrie RA, AlvarezBuylla A, Eisenman RN, Berger MS, Lin CH. Molecular Characteristics in MRI-Classified Group 1 Glioblastoma Multiforme. Front Oncol. 2013; 3:182.

50. Oliva CR, Markert T, Ros LJ, White EL, Rasmussen L, Zhang W, Everts M, Moellering DR, Bailey SM, Suto MJ, Griguer CE. Identification of small molecule inhibitors of human cytochrome c oxidase that target chemoresistant glioma cells. J Biol Chem. 2016; 291:24188-2 4199.

51. Alvero AB, Montagna MK, Holmberg JC, Craveiro V, Brown D, Mor G. Targeting the mitochondria activates two independent cell death pathways in ovarian cancer stem cells. Mol Cancer Ther. 2011; 10:1385-1 393.

52. Chen WH, Xu XD, Luo GF, Jia HZ, Lei Q, Cheng SX, Zhuo RX, Zhang XZ. Dual-targeting pro-apoptotic peptide for programmed cancer cell death via specific mitochondria damage. Sci Rep. 2013; 3:3468.

53. Don AS, Hogg PJ. Mitochondria as cancer drug targets. Trends Mol Med. 2004; 10:372-78.

54. D'Souza GG, Wagle MA, Saxena V, Shah A. Approaches for targeting mitochondria in cancer therapy. Biochim Biophys Acta. 2011; 1807:689-696.

55. Griguer CE, Oliva CR, Gillespie GY, Gobin E, Marcorelles P, Yancey Gillespie G. Pharmacologic manipulations of mitochondrial membrane potential (DeltaPsim) selectively in glioma cells. J Neurooncol. 2007; 81:9-20.
56. Guo R, Wang Y, Shi WY, Liu B, Hou SQ, Liu L. MicroRNA miR-491-5p targeting both TP53 and Bcl-XL induces cell apoptosis in SW1990 pancreatic cancer cells through mitochondria mediated pathway. Molecules. 2012; 17:14733-47.

57. Hagland H, Nikolaisen J, Hodneland LI, Gjertsen BT, Bruserud $\varnothing$, Tronstad KJ. Targeting mitochondria in the treatment of human cancer: a coordinated attack against cancer cell energy metabolism and signalling. Expert Opin Ther Targets. 2007; 11:1055-69.

58. Hockenbery DM, Giedt CD, O’Neill JW, Manion MK, Banker DE. Mitochondria and apoptosis: new therapeutic targets. Adv Cancer Res. 2002; 85:203-42.

59. Ma X, Wang X, Zhou M, Fei H. A mitochondria-targeting gold-peptide nanoassembly for enhanced cancer-cell killing. Adv Healthc Mater. 2013; 2:1638-43.

60. Pathania D, Millard M, Neamati N. Opportunities in discovery and delivery of anticancer drugs targeting mitochondria and cancer cell metabolism. Adv Drug Deliv Rev. 2009; 61:1250-75.

61. Ralph SJ, Low P, Dong L, Lawen A, Neuzil J. Mitocans: mitochondrial targeted anti-cancer drugs as improved therapies and related patent documents. Recent Patents Anticancer Drug Discov. 2006; 1:327-46.

62. Weinberg SE, Chandel NS. Targeting mitochondria metabolism for cancer therapy. Nat Chem Biol. 2015; 11:9-15.

63. Wen S, Zhu D, Huang P. Targeting cancer cell mitochondria as a therapeutic approach. Future Med Chem. 2013; 5:53-67.

64. Davey GP, Clark JB. Threshold effects and control of oxidative phosphorylation in nonsynaptic rat brain mitochondria. J Neurochem. 1996; 66:1617-24.

65. Davey GP, Peuchen S, Clark JB. Energy thresholds in brain mitochondria. Potential involvement in neurodegeneration. J Biol Chem. 1998; 273:12753-57.

66. Gnaiger E, Lassnig B, Kuznetsov A, Rieger G, Margreiter R. Mitochondrial oxygen affinity, respiratory flux control and excess capacity of cytochrome c oxidase. J Exp Biol. 1998; 201:1129-39.

67. Letellier T, Heinrich R, Malgat M, Mazat JP. The kinetic basis of threshold effects observed in mitochondrial diseases: a systemic approach. Biochem J. 1994; 302:171-74.

68. Sun AS, Cederbaum AI. Oxidoreductase activities in normal rat liver, tumor-bearing rat liver, and hepatoma HC-252. Cancer Res. 1980; 40:4677-81.

69. Sun AS, Sepkowitz K, Geller SA. A study of some mitochondrial and peroxisomal enzymes in human colonic adenocarcinoma. Lab Invest. 1981; 44:13-17.

70. Griguer CE, Oliva CR, Gobin E, Marcorelles P, Benos DJ, Lancaster JR Jr, Gillespie GY. CD133 is a marker of bioenergetic stress in human glioma. PLoS One. 2008; 3:e3655.

71. Griguer CE, Oliva CR, Kelley EE, Giles GI, Lancaster JR Jr, Gillespie GY. Xanthine oxidase-dependent regulation of hypoxia-inducible factor in cancer cells. Cancer Res. 2006; 66:2257-63. 
72. Tilson SG, Haley EM, Triantafillu UL, Dozier DA, Langford CP, Gillespie GY, Kim Y. ROCK Inhibition Facilitates In Vitro Expansion of Glioblastoma Stem-Like Cells. PLoS One. 2015; 10:e0132823.

73. Giannini C, Sarkaria JN, Saito A, Uhm JH, Galanis E, Carlson BL, Schroeder MA, James CD. Patient tumor EGFR and PDGFRA gene amplifications retained in an invasive intracranial xenograft model of glioblastoma multiforme. Neuro-oncol. 2005; 7:164-76.

74. Kitange GJ, Carlson BL, Mladek AC, Decker PA, Schroeder MA, Wu W, Grogan PT, Giannini C, Ballman KV, Buckner JC, James CD, Sarkaria JN. Evaluation of MGMT promoter methylation status and correlation with temozolomide response in orthotopic glioblastoma xenograft model. J Neurooncol. 2009; 92:23-31.

75. Sarkaria JN, Carlson BL, Schroeder MA, Grogan P, Brown PD, Giannini C, Ballman KV, Kitange GJ, Guha A, Pandita A, James CD. Use of an orthotopic xenograft model for assessing the effect of epidermal growth factor receptor amplification on glioblastoma radiation response. Clin Cancer Res. 2006; 12:2264-71.
76. Sarkaria JN, Yang L, Grogan PT, Kitange GJ, Carlson BL, Schroeder MA, Galanis E, Giannini C, Wu W, Dinca $\mathrm{EB}$, James CD. Identification of molecular characteristics correlated with glioblastoma sensitivity to EGFR kinase inhibition through use of an intracranial xenograft test panel. Mol Cancer Ther. 2007; 6:1167-74.

77. Rice MW, Smith KL, Roberts RC, Perez-Costas E, Melendez-Ferro M. Assessment of cytochrome C oxidase dysfunction in the substantia nigra/ventral tegmental area in schizophrenia. PLoS One. 2014; 9:e100054.

78. Kaila VR, Oksanen E, Goldman A, Bloch DA, Verkhovsky MI, Sundholm D, Wikstrom M. A combined quantum chemical and crystallographic study on the oxidized binuclear center of cytochrome c oxidase. Biochim Biophys Acta. 2011; 1807:769-778.

79. Sherman W, Day T, Jacobson MP, Friesner RA, Farid R. Novel procedure for modeling ligand/receptor induced fit effects. J Med Chem. 2006; 49:534-53. 